\title{
Optical Coherence Tomography Angiography (OCTA) in Ophthalmology; Technology, Pros, Cons and Commercial Prototypes
}

\author{
Joobin Khadamy * \\ Iran University of Medical Sciences (IUMS), Iran
}

Submission: February 21, 2017; Published: April 19, 2017

*Corresponding author: Joobin Khadamy, MD, Eye Research Center, Rassoul Akram hospital, Iran University of Medical Sciences (IUMS), Sattarkhan- Niayesh Street, Tehran 14456-13131, Iran, Tel: +989125394802, Fax: +982166509162; Email: joobin_kh@hotmail.com

\begin{abstract}
The OCTA is a novel evolving imaging technology which utilizes motion contrast to visualize retinal and choroidal vessels. It showed promises to be used in predicting, grading, guiding and following treatment of important ocular vascular diseases. The main advantages of the OCTA are being non-invasive; being blue light and dye free and providing high quality images in a relatively short time. It has alleviated important limitations of Fluorescein Angiography (FA), but still it is not considered as a complete substitute of FA, by experts. The Combined FA/ICGA and OCTA imaging systems are introduced to the market. It may have the advantages of the both systems, while having the least limitations. Resolution of images, field of view, depth of images and scan speed are important factors when choosing a device. But one should also take into account that higher image quality needs more time to be acquisitioned. It could be challenging in busy clinics. In this article we compared FA and OCTA and also compared widely available commercial prototype of OCTA devices.
\end{abstract}

\section{Introduction}

Optical Coherence Tomography Angiography (OCTA) is a novel imaging technology which has considerable advantages over older angiograms token by Fluorescein Angiography (FA) or Indocyanine Green Angiogarphy (ICGA). On top of them, one may list advantages like being non-invasive; no needs for dye; high resolution simultaneous visualization of the both retinal and choroidal vasculatures; simultaneous 3 dimensional (3D) visualization of retinal and choroidal structure; and possibility of segmentation of retinal layers and capillary plexuses in 3 layers including Superficial (SCP), Middle (MCP) and Deep (DCP) [1]. One of the promising features of this technology is that beside qualitative data, it provides quantitative data regarding retinal and choroidal structural and vascular indices like Vascular Density (VD), Foveal Avascular Zone (FAZ), etc. Feasible Quantitative data provided by OCTA; may revolutionize current ophthalmic practice in regards of predicting [2,3], grading [4,5], following up treatment in patients with important vascular diseases like diabetic retinopathy, retinal vein obstruction, choroidal neovascularization, etc. [6-10]. However, currently the quantitative data are mostly used for researches, But it seems that in the future when some cut off points are available by large scale studies. Then, these data could be used for everyday clinical practices. For an instance, quantitative assessment of Foveal Avascular Zone (FAZ) could be useful in optimal selection of therapy in patients with Diabetic Macular Edema (DME) [11] or even grading the severity of Diabetic Retinopathy (DR) $[5,12]$. It has also shown that FAZ metrics could change in response to treatment [6] so it could be used in following up patients. But a recent study has challenged these changes [13]. It should be emphasized that FA could also provide data regarding FAZ, but OCTA is more reliable, precise and also much more feasible. In FA, frequently dye leakage or DCP and SCP overlaps may influence the FAZ measurement [14]. Hereby, the OCTA technology, advantages, disadvantages and some commercial prototypes are discussed.

\section{Optical Coherence Tomography Angiography Technology}

The principal of this imaging system is detecting motion contrasts. This device record and compare multiple fast B-Scans of each vascular layer of retina. It simply presumes that the only motion inside retina is related to red blood cells (RBC) within vasculatures. These decorrelation signals are mapped in an OCT angiogram. Lastly, OCT B-Scan and OCT angiogram join together 
to visualize the both histological and vascular structures at the same time [15].

\section{Optical Coherence Tomography Angiography vs. Fluorescein Angiography}

Currently, FA and ICGA are gold standard in assessment of retinal and choroidal vasculatures. But the FA has considerable shortages like being invasive; being dye dependent; putting patients at possible dye mortal side effects (however, rare); clinical contraindications of dye; putting retina at risk of blue light toxicity; relative long picture acquisition time (some 15 minutes); disability in assessing deeper retinal or choroidal layers; disability in providing 3D pictures, disability in providing structural details of retina and choroid; and not providing quantitative data. It seems that OCTA has alleviated all above FA's limitations. However, as any other device, it has inherited some technical limitations [16,17]. One may count: more limited field of view; not providing functional data regarding vessels like not showing leakages; being more sensitive to small eye movements; needs for more patients' cooperation and ability to maintain proper fixation [18]. This later may make the acquisition time in real practice much longer than official announcements by manufacturers. Different commercial devices utilize various technologies to improve quality of picture by reducing motion artifacts [19]; through special algorithms (amplitude decorrelation algorithm, OCT-based or optical microangiography (OMAG) [20], split-spectrum amplitude decorrelation angiography (SSADA), etc.) [21]; and also improving the field and depth of pictures [22]. In this technology, we encounter day to day evolution of imaging system in terms of eye tracking systems; speed of picture acquisition; artifact reduction solutions [23]; field and depth of images [22]. Table 1 compares FA and OCTA. The invention of the combined imaging systems which provide a hybrid FA/ICGA and OCTA images may have the least limitations.

Table 1: Optical coherence tomography angiography and fluorescein angiography comparison

\begin{tabular}{|c|c|c|}
\hline Features & OCTA & FA \\
\hline Invasiveness & No & Yes \\
\hline Dye dependence & No & Yes \\
\hline Fluorescein side effect & No & Yes \\
\hline Blue light toxicity possibility & No & Yes \\
\hline Image dimensions & 3 Dimensional & 2 Dimensional \\
\hline Field of view (at most) & $12 \times 12 \mathrm{~mm}$ & Wider field is available \\
\hline Acquisition time [28] & $<5$ minute & 15 minute \\
\hline $\begin{array}{l}\text { Time sequence of circulation events (important } \\
\text { in delays or fast wash out) }\end{array}$ & NO & Yes \\
\hline Segmentation of layers & Yes & No \\
\hline Functional data like vascular leakage & No & Yes \\
\hline $\begin{array}{l}\text { Qualitative and quantitative assessment of FAZ } \\
\text { [29] }\end{array}$ & $\begin{array}{l}\text { Affected by shadows from hemorrhage and } \\
\text { macular edema }\end{array}$ & Affected by leakages and overlaps \\
\hline Distinguishing IRMA from neovascular tufts [30] & Yes & No \\
\hline Detecting Veins from arteries [31] & Not directly & Yes \\
\hline Direct visualization of depth of lesions & Yes & No \\
\hline $\begin{array}{l}\text { Feasible measurement of vascular lesions like } \\
\text { CNV }\end{array}$ & Yes & No \\
\hline
\end{tabular}

FA: Fluorescein Angiography; FAZ: Foveal Avascular Zone; OCTA: Optical Coherence.

Tomography Angiography; IRMA: Intraretinal Microvascular Abnormalities

Is it possible to Upgrade SD-OCT Devices to OCTA Device?

The SD-OCT devices can do 26 to 40 thousands scans per seconds while commercial OCTA's scan speed is some two-fold of this. The resolution of images (indirectly, as resolution is dependent on number of scan per section which is limited by fixed scan speed and acquisition time) and their sensitivity to motion artifacts is particularly dependent on this. So the SDOCT can not be utilized to obtain angiogram as images would be small and clinically useless. Fortunately, some manufacturers supplied their previous SD-OCT users with a two-step SD-OCT to OCTA upgrade. Firstly, they upgrade the hardware of device to higher frequency scan device, then they install OCTA software module on the device.

\section{Commercial Prototypes Comparison}

Most commonly used device in clinical centers, is AngioVue (Opto Vue, Inc., Fremont, Calif., USA) [10]. Recently, Heidelberg 
Engineering has released its OCTA modules. AngioPlex (Zeiss Meditec, Inc., Dublin, Calif., USA) is also an other widely available

Table 2: Comparison of widely commercially available optical coherence tomography angiography devices.

\begin{tabular}{|c|c|c|c|}
\hline Features & Heidelberg, Spectralis $®$ OCTA & Optovue, AngioVue ${ }^{\mathrm{TM}}$ & ZEISS, Angio Plex ${ }^{\mathrm{TM}}$ \\
\hline Scan speed (per second) & 85,000 & 70,000 & 68,000 \\
\hline Field & Up to $55(16 \mathrm{~mm})$ & $8 \times 8 \mathrm{~mm}$ & $6 \times 6 \mathrm{~mm}$ \\
\hline Depth of imaging (mm) & 1.8 & 3 & 2 \\
\hline Acquisition time (seconds) & Not available & 3 & 3 \\
\hline Axial resolution (micron) & 3.9 & 5 & 5 \\
\hline Transverse resolution (micron) & 14 & 15 & 15 \\
\hline Image resolution (pixels) & $512 \times 512$ & $304 \times 304$ & $304 \times 304$ \\
\hline Focus range & -12 to +12 & -15 to +20 & -20 to +20 \\
\hline Combination with FA/ICGA & Possible & No & No \\
\hline Tracking system & True-Track $^{\mathrm{TM}}$ & Real time tracking & Fast Track ${ }^{\mathrm{TM}}$ \\
\hline Algorithm & amplitude decorrelation algorithm & SSADA & OMAG \\
\hline
\end{tabular}

All the values are retrived from official websites of manufacturers.

While choosing a device one should consider following issues. The higher the scan speed is, the lower the effect of motion artifact would be. And also the resolution of images depends on number of scans per section. As the scan speed and scan acquisition time are limited, so it should be taken in to account that the high resolution of image translate to more acquisition time which is challenging in busy clinics. It is the reason why some manufacturer has not announced their device acquisition time, officially. And also some have reduced their image quality. As the OCTA is not substitute of FA in expert opinions; and also it is considerably expensive technology; moreover, many clinics has physical space limitation; so devices that provide hybrid FA/ ICGA and OCTA, could be an all-in-one reasonable option.

\section{Future of Optical Coherence Tomography Angiography}

Currently, the clinical use of OCTA is limited by its' expensiveness; small field of imaging; slow acquisition time; quality of images; lack of cut off points for quantitative data; lack of defined clinical significance of enormous data provided.

While developers are trying to invent faster swept source devices; smarter eye tracking systems; and also reducing artifacts that could provide wider higher quality views in matter of seconds, clinicians should utilize massive data provided by this technology in their everyday clinical practice by investigating the clinical relevance of findings. As we are on the edge of new robotic era, there are promises that images of retina could be efficiently processed by computers to diagnosis and grade diseases [24] and also conjunction of surgical or laser devices with imaging system could revolutionize both the diagnosis and treatment of ocular diseases [25-31].

\section{References}

1. Park JJ, Soetikno BT, Fawzi AA (2016) Characterization of the Middle Capillary Plexus Using Optical Coherence Tomography Angiography in Healthy and Diabetic Eyes. Retina 36(11): 2039-2050.
2. De Carlo TE, Chin AT, Bonini FMA, Adhi M, Branchini L, et al. (2015) Detection of Microvascular Changes in Eyes of Patients with Diabetes but Not Clinical Diabetic Retinopathy Using Optical Coherence Tomography Angiography. Retina 35(11): 2364-2370.

3. Takase N, Nozaki M, Kato A, Ozeki H, Yoshida M, et al. (2015) Enlargement of Foveal Avascular Zone in Diabetic Eyes Evaluated by En Face Optical Coherence Tomography Angiography. Retina 35(11): 2377-2383.

4. Ahmad FM, Ngah NF, George TM, Izhar LI, Nugroho H, et al. (2010) Analysis of foveal avascular zone in colour fundus images for grading of diabetic retinopathy severity. Conf Proc IEEE Eng Med Biol Soc 2010: 5632-5635.

5. Khadamy J (2016) Can Foveal Avascular Zone (FAZ) Assessment By OCT Angiography, Used For Grading Of Diabetic Retinopathy? 5(3): 00160.

6. Miwa Y, Murakami T, Suzuma K, Uji A, Yoshitake S, et al. (2016) Relationship between Functional and Structural Changes in Diabetic Vessels in Optical Coherence Tomography Angiography. Sci Rep 6: 29064.

7. Nobre CJ, Keane PA, Sim DA, Bradley P, Agrawal R, et al. (2016) Systematic Evaluation of Optical Coherence Tomography Angiography in Retinal Vein Occlusion. Am J Ophthalmol 163: 93-107.

8. Glacet-BA, Sellam A, Coscas F, Coscas G, Souied EH, et al. (2016) Optical coherence tomography angiography in retinal vein occlusion treated with dexamethasone implant: a new test for follow-up evaluation. Eur J Ophthalmol 26(5): 460-468.

9. Bonini FMA, De Carlo TE, Ferrara D, Adhi M, Baumal CR, et al. (2015) Association of Choroidal Neovascularization and Central Serous Chorioretinopathy with Optical Coherence Tomography Angiography. JAMA Ophthalmol 133(8): 899-906.

10. Chalam KV, Sambhav K (2016) Optical Coherence Tomography Angiography in Retinal Diseases. J Ophthalmic Vis Res 11(1): 84-92.

11. Lee J, Moon BG, Cho AR, Yoon YH (2016) Optical Coherence Tomography Angiography of DME and Its Association with Anti-VEGF Treatment Response. Ophthalmology 123(11): 2368-2375.

12. Bhanushali D, Anegondi N, Gadde SG, Srinivasan P, Chidambara L, et al. (2016) Linking Retinal Microvasculature Features With Severity of Diabetic Retinopathy Using Optical Coherence Tomography Angiography. Invest Ophthalmol Vis Sci 57(9): 519-525. 
13. Ghasemi FK, Iafe NA, Hubschman JP, Irena T, Srinivas RS, et al. (2017) Optical Coherence Tomography Angiography Analysis of the Foveal Avascular Zone and Macular Vessel Density After Anti-VEGF Therapy in Eyes With Diabetic Macular Edema and Retinal Vein Occlusion. Invest Ophthalmol Vis Sci 58(1): 30-34.

14. Yu S, Lu J, Cao D, Liu R, Liu B, et al. (2016) The role of optical coherence tomography angiography in fundus vascular abnormalities. BMC Ophthalmol 16: 107.

15. De Carlo TE, Romano A, Waheed NK, Duker JS (2015) A review of optical coherence tomography angiography (OCTA). Int J Retina Vitreous 1: 5.

16. Soares M, Neves C, Marques IP, Isabel P, Christian S, et al. (2017) Comparison of diabetic retinopathy classification using fluorescein angiography and optical coherence tomography angiography. British Journal of Ophthalmology 101(1): 62-68.

17. Inoue M, Jung JJ, Balaratnasingam C, Dansingani KK, Dhrami-GE, et al. (2016) A Comparison Between Optical Coherence Tomography Angiography and Fluorescein Angiography for the Imaging of Type 1 Neovascularization. Invest Ophthalmol Vis Sci 57(9): 314-323.

18. De Carlo TE, Bonini FMA, Chin AT, Adhi M, Ferrara D, et al. Spectral Domain Optical Coherence Tomography Angiography (OCTA) of Choroidal Neovascularization. Ophthalmology 122(6): 1228-1238.

19. Spaide RF, Fujimoto JG, Waheed NK (2015) Image Artifacts in Optical Coherence Tomography Angiography. Retina 35(11): 2163-2180.

20. Wang RK, An L, Francis P, Wilson DJ (2010) Depth-resolved imaging of capillary networks in retina and choroid using ultrahigh sensitive optical microangiography. Opt Lett 35(9): 1467-1469.

21. Jia Y, Tan O, Tokayer J, Potsaid B, Wang Y, et al. (2012) Split-spectrum amplitude-decorrelation angiography with optical coherence tomography. Opt Express 20(4): 4710-4725.

22. Zhang A, Zhang Q, Chen CL, Wang RK (2015) Methods and algorithms for optical coherence tomography-based angiography: a review and comparison. J Biomed Opt 20(10): 100901.
23. Ghasemi FK, Al-SM, Akil H, Sadda SR (2016) Image artefacts in sweptsource optical coherence tomography angiography. Br J Ophthalmol 2016: 309104.

24.Gulshan V, Peng L, Coram M, Stumpe MC, Wu D, et al. (2016) Development and validation of a deep learning algorithm for detection of diabetic retinopathy in retinal fundus photographs. JAMA 316(22): 2402-2410.

25. Hubschman JP, Wilson J, Tsao TC, Schwartz S (2010) Robotic eye surgery. Ophthalmology 117(4): 857.

26. Beaudette K, Baac HW, Madore WJ, et al. (2015) Laser tissue coagulation and concurrent optical coherence tomography through a double-clad fiber coupler. Biomed Opt Express 6(4): 1293-1303.

27. Falavarjani KG, Wang K, Khadamy J, Sadda SR (2016) Ultra-wide-field imaging in diabetic retinopathy; an overview. J Curr Ophthalmol 28(2): 57-60.

28. De Vitis LA, Benatti L, Tomasso L, Giovanni B, Adriano C, et al. (2016) Comparison of the Performance of Two Different Spectral-Domain Optical Coherence Tomography Angiography Devices in Clinical Practice. Ophthalmic Res 56(3): 155-162.

29. Jia Y, Bailey ST, Hwang TS, McClintic SM, Gao SS, et al. (2015) Quantitative optical coherence tomography angiography of vascular abnormalities in the living human eye. Proc Natl Acad Sci USA 112(18): E2395-E23402.

30. Hwang TS, Jia Y, Gao SS, Bailey ST, Lauer AK, et al. (2015) Optical Coherence Tomography Angiography Features of Diabetic Retinopathy. Retina 35(11): 2371-2376.

31. Freiberg FJ, Pfau M, Wons J, Wirth MA, Becker MD, et al. (2016) Optical coherence tomography angiography of the foveal avascular zone in diabetic retinopathy. Graefes Arch Clin Exp Ophthalmol 254(6): 10511058.
Your next submission with Juniper Publishers will reach you the below assets

- Quality Editorial service

- Swift Peer Review

- Reprints availability

- E-prints Service

- Manuscript Podcast for convenient understanding

- Global attainment for your research

- Manuscript accessibility in different formats ( Pdf, E-pub, Full Text, Audio)

- Unceasing customer service

Track the below URL for one-step submission https://juniperpublishers.com/online-submission.php 